\title{
Vitamin D: Multiple impacts, new perspectives
}

\author{
Laura Florescu', Laura Mihaela Trandafir², Dana Elena Mindru', \\ Oana-Raluca Temneanu ${ }^{1}$ \\ ${ }^{1}$ Childcare Discipline, Department of Mother and Child Medicine \\ „Gr. T. Popa“ University of Medicine and Pharmacy, Iasi, Romania \\ 2Pediatric Discipline, Department of Mother and Child Medicine \\ „Gr. T. Popa“ University of Medicine and Pharmacy, Iasi, Romania
}

\begin{abstract}
Vitamin D deficiency is a global public health problem in all age groups, mainly caused by insufficient exposure to sunlight, inadequate diets, inefficient absorption and use, higher requirements or higher losses. Knowing the implications of vitamin $\mathrm{D}$ for the body and sensitive growth and development periods, it is important to perform biological determinations, to make proper prophylaxis and to intervene promptly when changes occur. The age groups recommended for vitamin D administration are infants (whether they receive natural, formula or complementary feeding) and adolescents. Besides the well-known role of vitamin D in phosphocalcic metabolism, there is an increasing debate about the involvement of vitamin $\mathrm{D}$ in the pathogenesis of non-musculoskeletal diseases.
\end{abstract}

Keywords: vitamin D, cholecalciferol, vitamin D deficiency, phosphocalcic metabolism, rickets

Rickets, which has been described in literature since the 17 th century, has been associated with vitamin D deficiency years later, once it was possible to understand the metabolism of vitamin D and its mechanism of action in target organs. Between 1920 and 1940, vitamin D, originally known under the name "sunflower's vitamin", was classified as a vitamin rather than a steroid hormone.

However, photochemical production of vitamin D has been demonstrated by exposure to the sun, consequently proving that it becomes a real vitamin only in the absence of regular exposure to sunlight or ultraviolet light. The 1650-1963 period represented an important step in determining the chemical structures of vitamin $\mathrm{D}$, and the role in biological, clinical or nutritional sciences was later recognized (1).

Contrary to its name, vitamin D is actually a steroid hormone, known for its important role in regulating calcium and phosphorus in the body, and mineralizing bones. More recently, it has become clear that vitamin D receptors are present in a wide variety of cells and that this hormone has biological effects that far outweight the control of phosphocalcic metabolism.
It is known that vitamin D is a liposoluble vitamin, naturally present in very few foods, added to others and available as a dietary supplement; It exists in two forms - D2 (ergocalciferol) obtained from yeast and plants and D3 (cholecalciferol), obtained from the diet by ingestion of the products containing vitamin $\mathrm{D}$ (oily fish and eggs), milk fortified with vitamin D or margarine and / or the use of multivitamins $(2,3)$.

It is also an endogenous product under the action of ultraviolet rays in the skin. The term vitamin $\mathrm{D}$ is an imprecise term in the way that it is referring to one or more members of a group of steroid molecules. Vitamin D obtained from sun exposure, food, and supplements is biologically inert and must be subjected to hydroxylation reactions in the body to be brought into an active biological form. This transformation takes place in two stages:

- In the liver, cholecalciferal is hydroxylated to 25-hydroxycholecalciferol by the enzyme 25-hydroxylase

- In the kidneys, 25-OH-cholecalciferol is converted by alpha-hydroxylase into 1,25-dihydroxy-cholecalciferol, the biologically active form. Later, it is transported in the blood and linked to carrier proteins (vitamin D-binding protein) (4). 


\section{VITAMIN D DEFICIENCY}

Vitamin D Deficiency is a global public health problem in all age groups, mainly caused by insufficient exposure to sunlight, inadequate diets, inefficient absorption and use, higher requirements or higher losses. Vitamin D deficiency is much more common than previously thought, especially among infants, adolescents, women and the elderly, but for many countries there is no reported data, so it cannot be properly quantified (5-7).

A multitude of factors and situations contribute to the emergence of the deficit of vitamin D. Fears related to the development of a neoplasm and cultural beliefs, can lead to the avoidance of exposure to sunlight, while hyperpigmentation of the skin and the inefficiency of the sun during the cold season can also actively contribute to reduced vitamin $\mathrm{D}$ synthesis in the skin. Strictly vegetarian or vegan diets, including unfortified vegetable milk, low vitamin $\mathrm{D}$ foods play a role in creating this deficiency as well. A special category is represented by the congenital vitamin D deficiency in the infant, the most frequent being caused by severe deficiency in pregnancy due to faulty intake, low sun exposure for those who live at northern latitudes or have had a small interval between pregnancies (8).

Other causes of this deficiency are represented by chronic liver and kidney diseases, which reduce conversion into active forms, increased vitamin D losses, intestinal absorption deficits (cystic fibrosis, celiac disease, short bowel syndrome), chronic consumption of certain drugs (anticonvulsants, immunosuppressants, chemotherapeutic, antituberculous, antacid, corticosteroids, anticoagulants,) excessive use of skin products with protective factor, stress $(9,10)$.

\section{CURRENT RECOMMENDATIONS ON VITAMIN D DEFICIENCY PROPHYLAXIS}

The American Academy of Pediatrics (2008) recommends adding vitamin $\mathrm{D}$ in any infant, the dose being of $400 \mathrm{IU} /$ day. For children and adolescents, the recommended dose is $400 \mathrm{IU} /$ day in a vitamin complex or an unique product with vitamin D (11). For Europe, the ESPGHAN (European Society for Paediatric Gastroenterology, Hepatology and Nutrition) Committee on Nutrition recommends a daily oral supplementation of 400 IU vitamin D for all infants during the first year of life. According to the European Food Safety Authority, the upper limit of safety is set at 1,000 IU/day for infants, 2,000 IU/day for children ages 1 to 10 years, and 4,000 IU/day for children and adolescents ages 11 to 17 years. For risk groups, oral supplementation of vitamin $\mathrm{D}$ must be taken into account beyond 1 year of age (12).

Vegetarian diets, due to their restrictive and unbalanced consumption, can easily lead to poor growth and deficiency in micro and macronutrients, so it is recommended to add vitamin D (13). Vitamin D supplementation for infants breastfed exclusively by vegetarian mothers is required only for limited exposure to sunlight, similar to nonvegetarian mothers. It is considered that lactose and lacto-ovo-vegetarian children should consume vitamin D fortified cow's milk in sufficient quantity, which implies that supplimentation with vitamin D is only necessary for vegan children with inadequate exposure to sunlight (14).

A special category is the majority of premature infants (98.9\%) who had vitamin D deficiency, half of which were severe. The risk of vitamin D deficiency has not been correlated with low gestational age (15).

\section{REFERENCE VALUES FOR SERUM VITAMIN D CONCENTRATION}

Serum concentration is the best indicator of vitamin D status. This reflects vitamin D produced by the skin and obtained from food and supplements. Reference values for plasma 25-hydroxyvitamin D $(25(\mathrm{OH}) \mathrm{D})$ concentrations are:

- Deficiency $<20 \mathrm{ng} / \mathrm{ml}(<50 \mathrm{nmol} / \mathrm{l})$

- Insufficient level: $20-30 \mathrm{ng} / \mathrm{ml}(50-75 \mathrm{nmol} / \mathrm{l})$

- Optimal level: 30-100 ng/ml (75-250 nmol/1)

- Excess $>100 \mathrm{ng} / \mathrm{ml}(>250)$

- Toxicity $>150 \mathrm{ng} / \mathrm{ml}$ (>325 nmol/l) (16).

The effects and implications of vitamin $D$ in the development and proper functioning of the human body have been and are still being studied. The classic manifestations of vitamin D deficiency, encountered in child and adult are rickets and osteomalacia; both reflect poor bone mineralization and usually result from a combination of inadequate exposure to sunlight and a decrease in vitamin $\mathrm{D}$ intake in the diet. But rickets have effects outside of bones and muscles, with cases of cardiomyopathy associated with low levels of $25(\mathrm{OH}) \mathrm{D}$ and rickets. In addition, although classic rickets mostly affect children aged 6-24 months up to 5 years, there are cases of rickets with hypocalcemic convulsions in adolescents (17).

Research suggests that vitamin D could play a role in the prevention and treatment of a number of 
different conditions, including diabetes, hypertension, cardiovascular disasase, allergy, immunity, brain, and nervous system, infectious disease, multiple sclerosis, and, apparently, influence the expression of genes involved in cancer development.

Obesity is a chronic, non-transmissible disease with multifactorial etiology, the prevalence of which is steadily increasing worldwide. Nowadays, especially for the pediatric age, it is considered to be one of the worst public health problems of the $21^{\text {st }}$ century. Obesity and vitamin D deficiency are two of the most important modifiable risk factors among chronic diseases. However, it remains controversial whether their association is constant or incidental (18).

Considering the physiological processes encountered in puberty and adolescence, it appears that supplementation with vitamin D contributes to weight loss and also to preventing bone demineralization in obese children with vitamin D deficiency (19).

Epidemiological and observational studies are focused on studying the relationship between vitamin D status and metabolic syndrome, adiposity markers and insulin resistance in children and obese adults. It is yet to be determined when exactly vitamin $\mathrm{D}$ intervenes to develop a public health strategy for cardio-metabolic diseases by preventing vitamin $\mathrm{D}$ deficiency. At the same time, being aware of the link between vitamin $\mathrm{D}$, homeostasis of phosphocalcic metabolism and the integrity of the osteo system, in particular, ensuring an optimal level of vitamin D doubled by a healthy lifestyle, can help prevent insulin resistance and diabetes $(20,21)$.

Current data shows that 25 hydroxyvitamin D is a strong immunomodulator which reduces systemic inflammation. The plasma level of vitamin D is inversely proportional to a series of pro-inflammatory biomarkers which are associated with insulin resistance development. Data from literature has shown that the prevalence of vitamin D deficiency would likely be higher in obese subjects, but the focus remains on whether vitamin $\mathrm{D}$ deficiency is the cause or the consequence of obesity.

It has been observed that hypovidaminosis $\mathrm{D}$ was associated with hyperglycemia, hyperinsulinemia, decreased beta-pancreatic cell function, and insulin resistance, therefore, with an increased risk of type 2 diabetes. However, the results emphasise the need for additional research in order to demonstrate with certainty if the optimum level of 25 $(\mathrm{OH}) \mathrm{D}$ could prevent type 2 diabetes $(22,23)$.
In observational studies, cardiovascular disease risk factors (CVD) are associated with low serum concentrations of $25(\mathrm{OH}) \mathrm{D}$. (24). The possible effects of vitamin D on blood pressure are explained by implication on endothelial dysfunction and modulation of the renin-angiotensin system. Thus, in hypertensive patients with low renin level, it has been observed that vitamin $\mathrm{D}$ treatment increased plasma renin activity (25).

Epidemiological evidence from the past decade suggests the involvement of vitamin $\mathrm{D}$ in the pathogenesis of food allergies. It has been noticed that the risk of food allergy was associated with the degree of sun exposure, latitude, the child's birth season, and the vitamin D serum level. An understanding of the role that vitamin D plays in the cellular and genetic immune system, as well as the interaction between microbe and vitamin $\mathrm{D}$, will provide insight into its impact on food allergies (26).

Vitamins and their metabolites have an important control function in immune homeostasis by influencing both innate and acquired immune responses. In recent decades, animal models have contributed significantly to understanding the pathophysiological mechanisms of allergic diseases such as asthma, anaphylaxis, or food allergy (27). The consistent evidence from animal studies on the multiple forms of impact of vitamins D and A on the immune system draws attention to their role in controlling allergies, but randomized controlled human studies are required. These findings highlight the importance of determining vitamin status in allergic patients, and especially for vitamin D (28). There are currently many studies with vitamin D supplements, which try to answer the question whether supplementation reduces the respiratory tract infections, including risk groups (infants, elderly, immunodeficiency, asthma, chronic obstructive pulmonary disease, dialysis, and HIV patients). In addition, more research needs to be carried out to further define the mechanisms by which vitamin $\mathrm{D}$ is able to regulate the immune responses to prevent or to reduce infectious status $(29,30)$.

Vitamin D deficiency has been related to a high number of pathologies, including skin cancer, autoimmune skin disorders, photodermatoses, atopic dermatitis and psoriasis, but it is clear that much more evidence is needed to comprehend the connections between vitamin $\mathrm{D}$ and skin pathology (31).

\section{CONCLUSIONS}

The prevalence of vitamin D deficiency and insufficiency is high and current data suggests an in- 
crease in the future. Vitamin D deficiency has been a widespread concern for public health over the past few years, given its numerous long-term implications. „Participation” of vitamin D deficiency is calcaemia, and is now increasingly being discussed in association with chronic non-musculoskeletal diseases such as cardiovascular disease, atopy, obesity, diabetes, autoimmune diseases, infections and neoplasia. In order to achieve appropriate prophywell-known in rickets, growth retardation, hypo-

laxis, it is necessary to keep in mind the stages of growth and development, starting with intrauterine life, each with different peculiarities and needs, as well as the family, environmental and lifestyle factors. Risk factors for vitamin D deficiency are various, some of them modifiable. Knowing the multiple implications of vitamin $\mathrm{D}$ in the body, there is more and more scientific proof suggesting the need for screening, drug supplementation in certain situations and targeted treatment.

\section{Conflict of interest: none declared Financial support: none declared}

\section{REFERENCES}

1. Norman A.W. The history of the discovery of vitamin $D$ and its daughter steroid hormone. Ann Nutr Metab. 2012; 61(3):199-206).

2. Zerwekh J.E. Blood biomarkers of vitamin D status. Am J Clin Nutr. 2008:87:1087-1091.

3. Cashman K.D., van den Heuvel E.G., Schoemaker R.J. et al. 25-Hydroxyvitamin D as a Biomarker of Vitamin D Status and Its Modeling to Inform Strategies for Prevention of Vitamin D Deficiency within the Population. Adv Nutr. 2017; 8(6):947-957.

4. Ionica E., Costache M. Biochimie generala, vol. III - Vitamine si elemente minerale. Bucuresti: Editura ARS DOCENDI, 2014.

5. Palacios C., Gonzalez L. Is vitamin D deficiency a major global public health problem? J Steroid Biochem Mol Biol. 2014; 144:138-145.

6. Holick M.F. Vitamin D deficiency. N Engl J Med. 2007; 357:266-281.

7. Ferrari D., Lombardi G., Banfi G. Concerning the vitamin D reference range: pre-analytical and analytical variability of vitamin $D$ measurement. Biochem Med. 2017; 27(3):030501.

8. Greenbaum L.A. Rickets and Hypervitaminosis D. In: Kliegman RM, Bonita MD, Schor NF et al. Nelson Textbook of Pediatrics. 20th edn. Philadelphia, PA: Elsevier, 2015:331-341.

9. Melamed M.L., Kumar J. Low Levels of 25-hydroxyvitamin D in the Pediatric Populations: Prevalence and Clinical Outcomes. Pediatr Health. 2010; 4(1):89-97.

10. Robien K., Oppeneer S.J., Kelly J.A. et al. Drug-vitamin D interactions: A systematic review of the literature. Nutr Clin Pract. 2013; 28(2):194-208.

11. Wagner C.L., Greer F.R. American Academy of Pediatrics Section on Breastfeeding; American Academy of Pediatrics Committee on Nutrition. Prevention of rickets and vitamin D deficiency in infants, children, and adolescents. Pediatrics. 2008; 122(5):1142-1152.

12. ESPGHAN Committee on Nutrition. Vitamin $D$ in the Healthy European Paediatric Population. JPGN. 2013;56: 692-701.

13. McEvoy C.T., Woodside J.V. Vegetarian Diets. In: Koletzko B, Bhutta ZA, Cooper P et al. Pediatric Nutrition in Practice 2nd, revised edn. Ettlingen: Karger; 2015:134-138.

14. Kleinman R.E. Nutritional Aspects of Vegetarian Diets. In: Kleinman RE (ed.). Pediatric Nutrition Handbook, ed 5. Elk Grove Village: American Academy of Pediatrics, 2004:191-208.

15. Park S.H., Lee G.M., Moon J.E. et al. Severe vitamin D deficiency in preterm infants: maternal and neonatal clinical features. Korean $J$ Pediatr. 2015; 58(11):427-433.

16. Alshahrani F., Aljohani N. Vitamin D: Deficiency, Sufficiency and Toxicity. Nutrients. $2013 ; 5(9)$ : 3605-3616.

17. Schnadower D., Agarwal C., Oberfield SE et al. Hypocalcemic seizures and secondary bilateral femoral fractures in an adolescent with primary vitamin D deficiency. Pediatrics. 2006; 118(5):22262230.

18. Wojcik M. Childhood Obesity and Vitamin D Deficiency. Endocrinol Diabetes Obes. 2013; 1(1):1004.
19. Szlagatys-Sidorkiewicz A., Brzeziński M., Jankowska A. et al. Long-term effects of vitamin $D$ supplementation in vitamin $D$ deficient obese children participating in an integrated weight-loss programme (a double-blind placebo-controlled study) - rationale for the study design. BMC Pediatr. 2017; 17(1):97.

20. Tangpricha V. Vitamin D Supplementation In Obese Africian American Children. J Clin Transl Endocrinol. 2018; 12:48-49.

21. Trandafir Laura Mihaela, Teslariu Oana, Toma Vasilica, Impactul deficitului de vitamina D în obezitatea copilului, in Managementul preventiv și interceptiv al afecțiunilor stomatologice la copil și adult tanar, sub redactia Adriana Bălan, Irina Zetu, Ed Gr.T.Popa UMF iași, 2016, 336-340

22. Park S.K., Garland C.F., Gorham E.D. et al. Plasma 25-hydroxyvitamin $\mathrm{D}$ concentration and risk of type 2 diabetes and pre-diabetes: 12-year cohort study. PLoS One. 2018; 13(4):e0193070. doi: 10.1371/journal.pone.0193070. eCollection 2018.

23. Moreira-Lucas T.S., Duncan A.M., Rabasa-Lhoret R. et al. Effect of vitamin $D$ supplementation on oral glucose tolerance in individuals with low vitamin D status and increased risk for developing type 2 diabetes (EVIDENCE): A double-blind, randomized, placebocontrolled clinical trial. Diabetes Obes Metab. 2017; 19(1):133-141.

24. Mirhosseini N., Rainsbury J., Kimball S.M. Vitamin D Supplementation, Serum 25(OH)D Concentrations and Cardiovascular Disease Risk Factors: A Systematic Review and Meta-Analysis. Front Cardiovasc Med. 2018; 5:87.

25. Wamberg L., Pedersen S.B., Rejnmark L. et al. Causes of Vitamin D Deficiency and Effect of Vitamin D Supplementation on Metabolic Complications in Obesity: a Review. Curr Obes Rep, 2015; 4:429_ 440.

26. Poole A., Song Y., Brown H. Cellular and molecular mechanisms of vitamin D in food allergy. J Cell Mol Med. 2018; 22(7):3270-3277.

27. Jensen-Jarolim E., Pali-Scholl I., Roth-Walter F. Outstanding animal studies in allergy I. From asthma to food allergy and anaphylaxis. Curr Opin Allergy Clin Immunol. 2017; 17:169-179.

28. Hufnagl K., Jensen-Jarolim E. Vitamin A and D in allergy: from experimental animal models and cellular studies to human disease. Allergo J Int. 2018; 27(3):72-78.

29. Gunville C.F., Mourani P.M., Ginde A.A. The Role of Vitamin D in Prevention and Treatment of Infection. Inflamm Allergy Drug Targets. 2013; 12(4):239-245.

30. Martineau A.R., Jolliffe D.A., Hooper R.L. et al. Vitamin D supplementation to prevent acute respiratory tract infections: systematic review and meta-analysis of individual participant data. BMJ. 2017; 356:i6583.

31. WULF H.C. The relation between skin disorders and vitamin D. British Association of Dermatologists. 2012; 166:471-473. 